\title{
Cytotoxic mechanisms in vitro against Epstein-Barr virus infected lymphoblastoid cell lines in rheumatoid arthritis
}

\author{
MICHAEL B McCHESNEY AND ARTHUR D BANKHURST \\ From the Department of Medicine, University of New Mexico School of Medicine, Albuquerque, New Mexico \\ 87131
}

SUMMARY Impaired regulation of latent infection with Epstein-Barr virus (EBV) may contribute to the pathogenesis of rheumatoid arthritis (RA) by allowing uncontrolled polyclonal $B$ cell activation. The control of EBV infection in vitro is dependent on several cytotoxic lymphoid cell populations. The present report examines the suppression of early lymphoblastoid outgrowth by natural killer (NK) like cells and the ability to form cytotoxic $\mathrm{T}$ lymphocytes (CTLs) specific for EBV in vitro. The latter was measured by a regression assay of EBV induced lymphoblastoid transformation. In this assay the regression of B cell outgrowth at four and six weeks is due to the generation of CTLs specific for EBV. Patients with RA were defective in this ability to generate CTLs. Eight out of nine patients with RA had a geometric mean at the $50 \%$ regression end point equal to or greater than $20 \times 10^{5}$ cells $/ \mathrm{ml}$. In contrast, the geometric mean for all control donors was less than $4 \times 10^{5}$ cell $/ \mathrm{ml}$. NK activity was measured by a conventional ${ }^{51} \mathrm{Cr}$ release assay with K562 targets. Patients with RA did not have significantly different activity from that of controls (RA patients, $n=4,45 \cdot 6 \pm 19 \cdot 7 \%(\bar{x} \pm S D)$ at $50: 1$, effector:target; normals, $\mathrm{n}=5,56 \cdot 6 \pm 5 \cdot 7 \%$ ). No spontaneous NK activity was detected against allogeneic or autologous EBV infected B cell targets. When peripheral mononuclear cells from patients were incubated for six days with interleukin-2, lysis of EBV infected targets was seen. No difference in this activity was seen between RA and control studies. Overall, these studies show that patients with RA are defective in their ability to generate CTLs specific for EBV in vitro.

Key words: natural cytotoxicity.

During the last several years it has become clear that patients with rheumatoid arthritis (RA) have several antibodies present which react with Epstein-Barr virus (EBV) antigens. Thus it has been proposed that a latent infection with EBV might contribute to the pathogenesis of RA by inducing polyclonal $B$ cell activation. ${ }^{1}$ If such a chronic EBV infection were present in RA patients, one might expect that an increased incidence of EBV related lymphomas might result, such as is the case in patients with the $\mathrm{X}$ linked lymphoproliferative syndrome ${ }^{2}$ or in re-

Accepted for publication 17 December 1985.

Correspondence to Dr Arthur D Bankhurst, Professor of Medicine, Department of Medicine, Albuquerque, New Mexico 87131 . cipients of organ transplants who receive thera- $\frac{D}{0}$ peutic immunosuppression. Such an increase in neoplasms, however, is not seen in RA patients. $\widetilde{\sigma}$ The control of early lymphoblastoid cell outgrowth $N$ is mediated by mononuclear cells with natural killer (NK) like properties and interferon. ${ }^{3}{ }^{4}$ The later control of EBV induced immunoglobulin secretion and the lysis of EBV infected cells is mediated by suppressor and cytotoxic $\mathrm{T}$ lymphocytes respectively. ${ }^{5-7}$ In order for a chronic EBV infection to occur which would result in persistent polyclonal B cell activation it would be logical to suggest that RA patients lack the ability to generate EBV specific cytotoxic $\mathrm{T}$ lymphocytes (CTLs). It has been reported, however, that RA patients do not have an 
impairment in their ability to generate EBV specific CTLs. ${ }^{7}$

The purpose of the present report was to reexamine whether there are defects in several cytotoxic mechanisms which could control EBV infection in RA patients. In contrast with the report mentioned above we have shown that generation of EBV specific CTLs in an outgrowth regression assay is defective in RA. ${ }^{8}$ In addition, we have shown that an interleukin-2 (IL-2) induced cytotoxic killer cell (LAK cell) can be generated in vitro which kills autologous B cells infected with EBV.

\section{Patients and methods}

\section{BLOOD DONORS}

Control subjects were normal individuals of both sexes between the ages of 22 and 50 years. Patient donors were selected from the rheumatology clinics at the University of New Mexico Hospital and the Albuquerque Veterans' Administration Medical Centre. Patients with RA met the criteria of the American Rheumatism Association for definite or classical RA, ${ }^{9}$ and were rheumatoid factor positive. The majority of patients had chronic active disease and were receiving multiple drug therapy, including non-steroidal anti-inflammatory agents. Several patients also received gold, penicillamine, or methotrexate. Patients with osteoarthritis had conventional clinical and radiographic evidence of disease and were receiving non-steroidal antiinflammatory agents. Donors were immune to EBV as determined by an indirect immunofluorescence test for IgG antibody to the viral capsid antigen. ${ }^{10}$

PREPARATION OF PERIPHERAL BLOOD

MONONUCLEAR CELLS

Peripheral blood mononuclear cells (PBMC) were isolated from heparinised venous blood by FicollHypaque density centrifugation, ${ }^{11}$ washed twice in phosphate buffered saline $\mathrm{pH} 7 \cdot 2$, and suspended in RPMI 1640 medium supplemented with $10 \%$ heat inactivated, fetal bovine serum (Hyclone Laboratories, Logan, UT), $1 \%$ penicillin and streptomycin, and $3 \mathrm{mM}$ glutamine.

\section{VIRUS}

The EBV producer cell line, B95-8, ${ }^{12}$ was a gift from Dr D Carson, Scripps Clinic and Research Foundation. Seven day culture supernates were prepared by ultracentrifugation and stored in culture medium with $10 \%$ dimethyl sulphoxide (Sigma, St Louis, MO) at $-70^{\circ} \mathrm{C}$. The virus stock, assayed by transformation of human cord blood lymphocytes, ${ }^{13}$ had $10^{3}$ transforming units $/ \mathrm{ml}$.
REGRESSION OFEBV INDUCED

LYMPHOBLASTOID TRANSFORMATION

This assay measures the concentration of PBMC at the start of culture required to generate $50 \%$ regression of EBV induced lymphoblastoid transformation. ${ }^{8}$ PBMC at $1 \times 10^{7}$ cells/ml were incubated with the virus stock for one hour at $37^{\circ} \mathrm{C}$. After washing in medium the cells were resuspended in RPMI 1640 supplemented with $20 \%$ heat inactivated, fetal bovine serum, $1 \%$ penicillin and streptomycin, and $3 \mathrm{mM}$ glutamine. Serial one to two dilutions of cells, from $2 \times 10^{6}$ cells $/ \mathrm{ml}$ to $1.25 \times 10^{5}$ cells $/ \mathrm{ml}$, were added to flat bottomed microtitre Linbro plates (Flow Laboratories, Inc., Hamden. CT) in a volume of $0.2 \mathrm{ml}$. Six wells were plated per dilution. The plates were placed at $37^{\circ} \mathrm{C}$ in a $5 \%$ $\mathrm{CO}_{2}$ incubator and replenished with $0.1 \mathrm{ml}$ fresh medium weekly. Cultures were observed by inverted stage light microscopy at four and six weeks for evidence of lymphoblastoid transformation. Viable transformation cultures had two or more large clumps of viable cells per well. Regression cultures contained only dead cells or only one small clump of viable cells per well. The cultures were scored for each initial cell concentration as the number of wells out of six showing transformation at six weeks. Negative control cultures consisted of uninfected PBMC and positive control cultures consisted of EBV infected PBMC incubated with cyclosporin A (gift of J Borel, Sandoz Ltd, Basel, Switzerland), $100 \mathrm{ng} / \mathrm{ml}$, during the first week of culture. Cyclosporin A allows the outgrowth of lymphoblastoid cells at high cell concentration. ${ }^{14}$ The initial cell concentration required to achieve a $50 \%$ regression end point was calculated by the method of Reed and Muench. ${ }^{15}$

\section{CEL L LINES}

The K562 cell line derived from a human myeloid leukaemia was used as an NK target. ${ }^{16}$ Lymphoblastoid cell lines (LCLs) were derived from EVB infected cultures in the regression experiments. The cell lines were maintained in RPMI 1640 supplemented with $10 \%$ fetal bovine serum replenished with fresh medium every three or four days. LCLs were shown to contain the EBV genome by the anticomplement immunofluorescence test for Epstein-Barr nuclear antigen. ${ }^{17}$

NATURAL CYTOTOXICITY ASSAY

A standard four hour chromium release assay was used as previously described. ${ }^{18}$ Cells from log phase cultures of K562 and the LCLs were labelled with chromium-51 sodium chromate, specific activity 200-500 Ci/g chromium (New England Nuclear, Boston, MA) for one and six hours respectively. 
Target cells at $1 \times 10^{5} / \mathrm{ml}$, and unfractionated PBMC at $5 \times 10^{6} / \mathrm{ml}$ were suspended in RPMI 1640 supplemented with $10 \%$ fetal bovine serum and plated in round bottomed microtitre Linbro plates in a final volume of $0.2 \mathrm{ml}$. The plates were incubated for four hours in a $5 \% \mathrm{CO}_{2}$ incubator at $37^{\circ} \mathrm{C} .0 .1 \mathrm{ml}$ of supernatant was aspirated from the top of the wells, and the radioactivity released was counted in a Packard A $800 \mathrm{C}$ gammacounter. Control counts for spontaneous release were obtained from wells containing only target cells.

Maximal release was determined with labelled target cells lysed with detergent. Specific lysis was calculated from triplicate data by the formula:

$$
\begin{gathered}
\text { Percentage } \\
\text { specific } \\
\text { lysis }
\end{gathered}=\frac{\text { experimental release }- \text { spontancous releasc }}{\text { maximal release }- \text { spontancous relcasc }} \times 100
$$

Spontaneous release from the K562 cell line was less than $10 \%$ of maximal release, and spontaneous release from the LCLs averaged $30 \%$ of maximal release.

LYMPHOKINE ACTIVATED KILLER CELLS $1 \times 10^{7}$ PBMC were cultured in RPMI 1640 medium with $10 \%$ human $\mathrm{AB}$ serum (in preliminary experiments fetal bovine serum was cytotoxic), $1 \%$ penicillin and streptomycin, $3 \mathrm{mM}$ glutamine, and $10 \%$ IL-2 (Electro-Nucleonics, Inc., Silverspring, MD) in $15 \times 60 \mathrm{~mm}$ plastic Petri dishes (Lab Tek Division, Miles Laboratories, Inc., IL). The IL-2 was a column purified preparation from lectin stimulated pooled human PBMC containing 640 units $/ \mathrm{ml}$, and was free from lectin or gamma interferon. ${ }^{19} \mathrm{Un}$ treated control cultures that did not contain IL-2 were set up in parallel with RPMI 1640. Cultures were supplemented with $10 \%$ IL-2 or RPMI 1640 at 48 and 96 hours. After six days of culture nonadherent cells were recovered, washed twice in RPMI 1640, counted, and resuspended in culture medium with $10 \%$ human $\mathrm{AB}$ serum and $10 \%$ IL-2. At this stage cells from IL-2 supplemented cultures and from untreated control cultures were treated in the same way. In preliminary experiments IL-2 present in the assay did not augment lysis by the untreated control PBMC. Cell recovery averaged $25-50 \%$ of the starting cell number, and viability averaged $80 \%$ by trypan blue dye exclusion. Cytotoxic effector function was assayed as described for the natural cytotoxicity assay.

\section{STATISTICAL METHODS}

The statistical differences between the results were analysed by the following methods: firstly, the difference between geometric differences was deter- mined by an analysis of variance (non-parametric, one way; Kruskal-Wallis); secondly, the difference? in proportions was evaluated by $\chi^{2}$ or Fisher's exact test, or both.

\section{Results}

REGRESSION OF EBV INDUCED

LYMPHOBLASTOID TRANSFORMATION

After in vitro infection of PBMC with EBV and $\vec{P}$ subsequent culture clumps of proliferating, growth transformed B lymphocytes emerge after 14 days. ${ }^{20} \vec{\omega}$ In cultures of PBMC from immune normal donors $\stackrel{\rho}{\Omega}$ these EBV infected cells die and result in dead cell clumps after four to six weeks. This phenomenon, regression of B lymphoblastoid outgrowth, is dependent on the cell concentration at the start of culture, or with regression observed in cultures plated at 2,1 , $\vec{\sigma}$ or $0.5 \times 10^{6} \mathrm{cells} / \mathrm{ml} .{ }^{8}$ No regression occurs in cultures을 of PBMC from non-immune donors. Regression is due to the generation of CTLs in culture that kill the $c$ virus infected B lymphocytes. ${ }^{20} 21$ These CTLs are specific for EBV and HL-A restricted. ${ }^{22}$ Cultures $\vec{\bullet}$ can be scored visually for the presence or absence of ${ }^{\infty}$ clumps of proliferating cells by inverted stage light microscopy, and replicate data can be used to calculate a $50 \%$ regression end point. The regression end point is reproducible in a given donor over time. $^{8}$

In the present experiments, after EBV infection of PBMC from normal donors and from patients $\overline{\bar{O}}$ with RA or osteoarthritis, the cells were plated in serial dilutions from $2 \cdot 0$ to $0 \cdot 125 \times 10^{6} / \mathrm{ml}$ in flat bottomed microtitre plates and incubated at $37^{\circ} \mathrm{C}$. Cultures were replenished weekly with fresh medium. Lymphoblastoid transformation or re-응 gression was scored at four and six weeks. The final 3 score at six weeks was used to calculate a $50 \%$ regression end point (Table 1). The geometric mean $50 \%$ regression end point for nine normal donors was $1 \cdot 8 \pm 0 \cdot 7 \times 10^{5}$ cells $/ \mathrm{ml}$. Normal donor number $10^{\circ}$ was non-immune, and his PBMC were unable to generate regression (Table 1). PBMC from nine RA donors, all immune to $\mathrm{EBV}$, had a $50 \%$ regression $N$ end point ranging from $1.9 \times 10^{5}$ cells $/ \mathrm{ml}$ to greater than $20 \times 10^{5}$ cells $/ \mathrm{ml}$, the upper limit of detection inN this assay (Table 1). RA donor number one, the ${ }^{\omega}$ only RA donor with a value in the normal range, had had definite RA for one and a half years but was? in clinical remission for six months at the time of the assay. RA donor number two had had definite $\mathrm{RA}^{-}$ for six months, with active disease at the time of the assay and was receiving no medication other than occasional aspirin in low dose. The other RA donors? had longstanding, chronically active disease. The 2 four control patients with osteoarthritis had $50 \% 2$ 
Table 1 RA patients have decreased EVB specific CTLs as measured in outgrowth regression assays

\begin{tabular}{|c|c|c|c|c|c|}
\hline $\begin{array}{l}\text { Normal } \\
\text { donor No }\end{array}$ & Cells $\times 10^{-5} / \mathrm{ml}$ & $\begin{array}{l}\text { Rheumatoid } \\
\text { donor No }\end{array}$ & Cells $\times 10^{-5} / \mathrm{ml}$ & $\begin{array}{l}\text { Osteoarthritis } \\
\text { donor No }\end{array}$ & Cells $\times 10^{-5} / \mathrm{ml}$ \\
\hline 1 & $<1.25^{*}$ & 1 & 1.9 & 1 & $1 \cdot 25$ \\
\hline 2 & $<1.25$ & 2 & $19 \cdot 1$ & 2 & $1 \cdot 5$ \\
\hline 3 & 1.6 & 3 & $20 \cdot 0$ & 3 & $1 \cdot 6$ \\
\hline 4 & 1.6 & 4 & $20 \cdot 0$ & 4 & 1.9 \\
\hline 5 & 1.7 & 5 & $>20 \cdot 0$ & & \\
\hline 6 & $1 \cdot 8$ & 6 & $>20 \cdot 0$ & & \\
\hline 7 & $1 \cdot 8$ & 7 & $>20 \cdot 0$ & & \\
\hline 8 & $2 \cdot 5$ & 8 & $>20 \cdot 0$ & & \\
\hline 9 & $3 \cdot 6$ & 9 & $>20 \cdot 0$ & & \\
\hline 10 & $>20 \cdot 0$ & & & & \\
\hline
\end{tabular}

${ }^{*}$ Cell concentration for $50 \%$ regression of EBV induced lymphoblastoid transformation. All donors, except for normal donor No 10 , are immune. Data are $50 \%$ regression end point calculations by the method of Reed and Muench ${ }^{15}$ (see 'Patients and methods'). There is a significant difference between RA patients and normal subjects or patients with osteoarthritis $(p<0 \cdot 01)$.

regression end points in the normal range. In several experiments monocyte depletion by adherence to glass Petri dishes for one hour before infection with EBV and culture had no effect on the poor regression in cultures of RA donors (data not shown).

\section{NATURAL CYTOTOXICITY AGAINST EBV}

IN FECTED LCLS

NK lysis of virus infected or tumour derived cell lines by PBMC is well defined in normal donors and is defective in some patients with chronic disease. ${ }^{23}$ Using unfractionated PBMC in a four hour chromium release assay at an effector:target ratio of 50:1, lysis of autologous and allogeneic EBV infected LCLs was compared with lysis of a standard human NK sensitive target, K562. Experiments were performed with five normal donors and four of the RA donors used in the regression assay experiments. The mean percentage specific lysis of K562 was $56 \cdot 5 \%$ with the normal donors and $45.6 \%$ with the RA donors (Table 2). There was no lysis of autologous or
Table 2 Natural cytotoxicity against K562, autologous or allogeneic $E B V$ infected $L C L S$

\begin{tabular}{llll}
\hline & K562 & $\begin{array}{l}\text { Allogeneic } \\
\text { LCLs }\end{array}$ & $\begin{array}{l}\text { Autologous } \\
\text { LCLs }\end{array}$ \\
\hline Normal $(\mathrm{n}=5)$ & $56 \cdot 5 \pm 5 \cdot 7^{*}$ & 0 & 0 \\
RA $(\mathrm{n}=4)$ & $45 \cdot 6 \pm 19 \cdot 7$ & 0 & 0 \\
\hline
\end{tabular}

*Data are mean $\pm 1 \mathrm{SD}$, percentage specific lysis, based on a four hour chromium release assay, effector:target ratio $=50: 1$.

allogeneic LCLs by either normal or RA donor PBMC (Table 2). In other experiments lytic activity against EBV infected LCLs could not be generated from normal donor PBMC that had been infected with EBV and cultured for one to seven days, while lysis of K562 remained raised for that time (data not shown).

LYMPHOKINE ACTIVATED KILLING OF EBV IN FECTED LCLS

Culture of PBMC for several days in the presence of exogenous IL-2 yields LAK cells which can lyse both

Table 3 Measurement of LAK cytotoxicity in RA patients

\begin{tabular}{|c|c|c|c|c|}
\hline \multirow{2}{*}{$\begin{array}{l}\text { Cell } \\
\text { source }\end{array}$} & \multirow[t]{2}{*}{$I L-2$ present } & \multicolumn{3}{|c|}{ Targets* } \\
\hline & & $K 562$ & $\begin{array}{l}\text { Autologous } \\
\text { LCLs }\end{array}$ & $\begin{array}{l}\text { Allogeneic } \\
\text { LCLs }\end{array}$ \\
\hline Normal, immune & $\overline{+}$ & $\begin{array}{l}22 \cdot 4^{+} \\
90 \cdot 0\end{array}$ & $\begin{array}{c}0 \\
49 \cdot 8\end{array}$ & $\begin{array}{c}0 \\
52 \cdot 9\end{array}$ \\
\hline Normal, non-immune & + & $\begin{array}{l}19 \cdot 2 \\
90 \cdot 1\end{array}$ & $\begin{array}{c}0 \\
35 \cdot 9\end{array}$ & $\begin{array}{c}0 \\
31 \cdot 6\end{array}$ \\
\hline RA, immune & - & $\begin{array}{l}22 \cdot 9 \\
83 \cdot 1\end{array}$ & $\begin{array}{c}0 \\
35 \cdot 5\end{array}$ & $\begin{array}{c}0 \\
29 \cdot 8\end{array}$ \\
\hline
\end{tabular}

${ }^{*}$ Cytotoxicity against K562, autologous and allogeneic EBV infected LCLs is recorded as percentage specific lysis from quadruplicatc data for the donor in a four hour chromium -51 release assay at effector:target ratio of 50:1. The data represent one of five experiments with different donors.

†The SD of all experimental values was less than $10 \%$. 

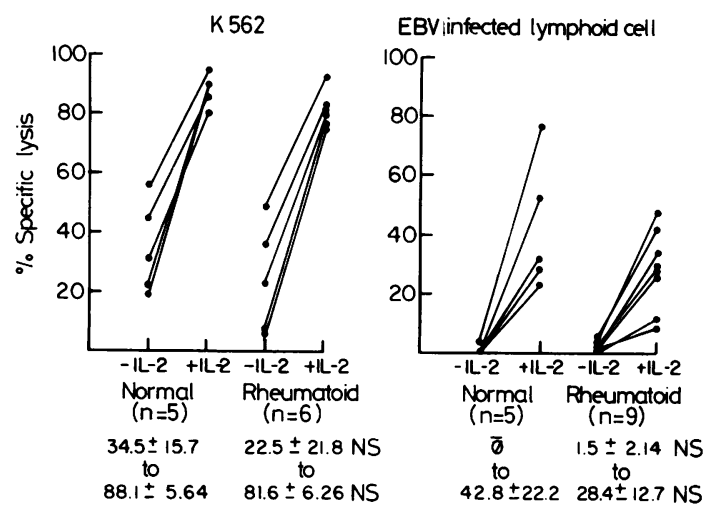

Fig. 1 NK and LAK cytotoxicity of patients with rheumatoid arthritis. Results are expressed as percentage specific lysis, mean $\pm I S D$. There was no difference between normal and rheumatoid patients using either K562 or EBV infected lymphoid cells.

conventional NK sensitive and NK resistant targets. ${ }^{24}$ Unfractioned PBMC from normal and RA donors were cultured for six days with or without exogenous IL-2. Fresh non-toxic human AB serum was used in this culture and in the subsequent chromium release assay. The cultures were supplemented with fresh IL-2 or RPMI 1640 at two and four days. At the end of culture non-adherent cells were recovered, washed, and plated in a four hour chromium release assay in fresh medium with $10 \%$ IL-2. Target cells, either K562 or autologous or allogeneic EBV infected LCLs, were added at an effector:target ratio of 50:1. Percentage specific lysis was calculated as in the NK assay. Spontaneous release from the LCL targets averaged $30 \%$ of maximal release. Data from one of five experiments are presented in Table 3. IL-2 in culture augmented lysis of K562 cells and expanded the target cell repertoire to NK resistant, EBV infected LCLs. When the immune and non-immune normal donors were compared no antigen specificity or HL-A restriction in LCL target lysis was found (Table 3). The PBMC from RA patients were able to generate cytotoxicity against EBV infected LCLs at a level comparable with that of the normal donors (Table 3 ). Data from the five experiments are shown in Fig. 1. There was no significant difference between RA patients and normal subjects in the level of cytotoxicity against EBV infected LCL targets by LAK cells.

\section{Discussion}

We have examined the ability of RA patients to control EVB induced lymphoblastoid outgrowth by three distinct cytotoxic mechanisms in vitro: classical virus specific CTLs, NK function based on lysis of K562 in a standard chromium release assay, ando LAK cell cytotoxicity. Regression of EBV induced흠 lymphoblastoid transformation due to classical, $\frac{\bar{\omega}}{\bar{D}}$ virus specific CTLs is dependent on cell concen- $\stackrel{\odot}{\circ}$ tration. Long lived memory $\mathrm{T}$ cells are diluted to a critically low level in this assay, so that the $50 \%$ regression end point is an approximation of the relative number of precursor CTLs in peripheral $\vec{\omega}$ blood. The differentiation of CTLs in vitro, however, involves a complex interaction of multiple cell types and lymphokines. ${ }^{25}$ It is not known which ${ }_{0}^{2}$ cell type is critically diluted in the regression assay. or The poor regression or absence of regression in our of RA samples is supported by the work of other $\vec{\sigma}$ laboratories, which showed poor regression by응 PBMC from RA donors compared with normals and patients with osteoarthritis. ${ }^{26-28}$ Tsoukas et al, $\subseteq$ however, have shown that when EBV specific CTLs are generated in vitro by another method- $\vec{\bullet}$ coculture of peripheral blood lymphocytes with mitomycin C treated, autologous EBV infected LCLs in two stages over 23 days-normal levels of EBV specific cytotoxicity are generated by RA patients in a four hour chromium release assay. ${ }^{7}$ It must be concluded from the later experiments that $\frac{\mathscr{D}}{\varnothing}$ precursors of EBV specific CTLs present in the peripheral blood of RA patients can differentiate $\overrightarrow{\bar{o}}$ under optimal conditions of antigen presentation in 3 culture. EBV specific CTL precursor frequency analysis by limiting dilution in normals or RA patients has not been reported to our knowledge. The significance of poor outgrowth regression in $\mathrm{RA}^{\circ}$ ? is thus unknown. In this assay perhaps inhibitory cells or soluble factors suppress differentiation of CTLs at high cell concentrations in RA: a condition not present in the culture of normal PBMC.

Natural cytotoxicity was normal in the RA? patients, while there was no lysis of autologous or $\frac{D}{0}$ allogeneic EBV infected LCLs by PBMC from normals or RA patients. Other investigators have $\mathcal{N}$ found normal levels of natural cytotoxicity in $N$ RA. ${ }^{23}{ }^{28}$ EBV infected LCLs derived from non- $N$ malignant B lymphocytes are relatively NK resistant. One group of investigators reported that RA lymphocytes do not lyse EBV infected LCLs in a short term chromium release assay. ${ }^{29}$ In marked contrast with these observations, there was definite lysis of $\mathrm{EBV}^{-}$ infected LCLs by normal and RA LAK cells ${ }^{-}$ generated in vitro. The LAK cell, defined by Grimm $\stackrel{\overrightarrow{\mathbb{D}}}{\mathrm{D}}$

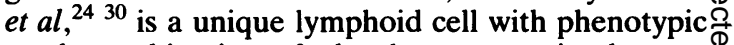
markers, kinetics of development, stimulus re- $\varrho$ quirement, and target cell specificity distinct from that of both CTLs and NK cells. The induction of 
LAK cells is IL-2 specific: interferons, IL-1, or migration inhibitory factor will not induce their formation. ${ }^{31}$ The in vivo significance of the LAK cell remains unknown. We have shown that LAK cells are also cytolytically competent against virus infected targets that are NK resistant in normals and in RA patients. We have not, however, shown by growth kinetics or cell phenotype analysis that our LAK cell is the same as that described by Grimm et al. ${ }^{24}$ CTL precursors can differentiate in the presence of IL-2 without specific antigenic stimulation. ${ }^{32}$ It is unlikely that an EBV specific CTL precursor is the major cell type that differentiates in response to IL-2 in the LAK assay because we have shown that non-immune PBMC are as effective as immune PBMC. Cells with phenotypic similarities to the LAK cell that can lyse EBV infected LCLs have been described in the blood of patients with infectious mononucleosis and were generated in vitro by $\mathrm{T}$ cell growth factor or by autologous mixed lymphocyte culture. ${ }^{33} \mathrm{~A}$ relevance of the LAK cell phenomenon to the pathology of RA is suggested by the findings of IL-2 activity in rheumatoid synovial fluid, ${ }^{34}$ and of NK like cells in rheumatoid synovial fluid that can lyse EBV infected LCLs, although at low levels. ${ }^{29}$

In summary, patients with RA possess defects in their ability to generate EBV specific CTLs in outgrowth regression assays. In addition, despite the presence of normal NK activity against conventional NK sensitive targets, RA patients are able to generate LAK cells in vitro that kill EBV infected autologous B cells. It still remains unclear what is the relation between these in vitro findings and the potential role of persistent $\mathrm{EBV}$ in the pathogenesis of RA.

This work was supported by grant No NIH R01 CA-24873. MBMcC was supported by NIH training grant 5 T32 AM 07173 .

\section{References}

1 Depper J M, Zvaifler N J. Epstein-Barr virus, its relationship to the pathogenesis of rheumatoid arthritis. Arthritis Rheum 1981: 24: 755-61.

2 Purtilo D T. Immunopathology of X-linked lymphoproliferative syndrome. Immunol Today 1983; 4: 291-7.

3 Shope T C, Kaplan J. Inhibition of the in vitro outgrowth of Epstein-Barr virus-infected lymphocyte by $\mathrm{T}_{\mathrm{G}}$ lymphocytes. $J$ Immunol 1979; 123: 2150-5.

4 Thorley-Lawson D A. The transformation of adult but not newborn human lymphocytes by Epstein-Barr virus and phytohemagglutinin is inhibited by interferon: the early suppression by $T$ cells of Epstein-Barr infection is mediated by interferon. $J$ Immunol 1981: 126: 829-33.

5 Tosato G, Magrath I T, Blaese R M. T cell-mediated immunoregulation of Epstein-Barr virus-(EBV) induced $B$ lymphocyte activation in EBV-seropositive and EBVseronegative individuals. $J$ Immunol 1982: 128: 575-9.
6 Tosato G, Steinberg A D, Blaese R M. Defective EBV-specific suppressor T-cell function in rheumatoid arthritis. $N$ Engl J Med 1981: 305: 1238-43.

7 Tsoukas C D, Carson D A, Fong S, Slovin S F, Fox R I. Vaughan $\mathrm{J} H$. Lysis of autologous Epstein-Barr virus-infected B cells by cytotoxic $T$ lymphocytes of rheumatoid arthritis patients Clin Immunol Immunopathol 1982: 24: 8-14.

8 Moss D J, Rickinson A B, Pope J H. Longterm T-cell-mediated immunity to Epstein-Barr virus in man. I. Complete regression of virus-induced transformation in cultures of seropositive donor leukocytes. Int J Cancer 1978; 22: 662-8.

9 Ropes M W. Bennett G A. Caleb S, Jacox R, Jesser R A. 1958 revision of diagnostic criteria for rheumatoid arthritis. Bull Rheum Dis 1958; 9: 175-6.

10 Andiman W A. Miller G. Antibody responses to Epstein-Barr virus. In: N R Rose, H Friedman, eds. Manual of clinical immunology. 2nd ed. Washington, DC: Am Soc for Microbiol, 1980: 631 .

11 Boyum A. Isolation of mononuclear cells and granulocytes from human blood. Scand J Clin Lab Invest 1968; 21 (suppl 97): $77-89$.

12 Miller G. Lipman M. Release of infectious Epstein-Barr virus by transformed marmoset leukocytes. Proc Natl Acad Sci USA 1973: 70: $190-4$.

13 Moss D J. Pope J H. Assay of the infectivity of Epstein-Barr virus by transformation of human leukocytes in vitro. $J$ Gen Virol 1972; 17: 233-6.

14 Bird A G, McLachan S M. Britton S. Cyclosporin A promotes spontaneous outgrowth in vitro of Epstein-Barr virus-induced B-cell lines. Nature 1981; 289: 300-1.

15 Reed L J. Muench $\mathrm{H}$. A simple method for estimating fifty percent endpoints. Am J Hyg 1938; 27: 493-7.

16 Klein E. Ben-Hassat H, Newman H. Properties of the K562 cell line derived from a patient with chronic myeloid leukemia. Int $J$ Cancer 1976; 18: 421-31.

17 Reedman B M. Klein G. Cellular localization of an EpsteinBarr virus associated complement-fixing antigen in producer and non-producer lymphoblastoid cell lines. Int J Cancer 1973; 11: $499-520$.

18 Bankhurst A D. The modulation of human natural killer cell activity by prostaglandins. J Lab Clin Immunol 1982; 7: 85-93.

19 Product brochure for purified human IL-2. Silver Spring, M D: Electro Nucleonics. Inc.

20 Thorley-Lawson D A. Chess L. Strominger J L. Suppression of in vitro Epstein-Barr virus infection: a new role for adult human T lymphocytes. J Exp Med 1977: 146: 495-508.

21 Moss D J, Rickinson A B. Pope J H. Long-term T-cellmediated immunity to Epstein-Barr virus in man. III. Activation of cytotoxic T cells in virus-infected leukocyte cultures. Int $J$ Cancer 1979; 23: 618-25.

22 Rickinson A B. Wallace L E. Epstein M A. HLA-restricted Tcell recognition of Epstein-Barr virus-infected B cells. Nature 1980; 283: 865-7.

23 Neighbour P A. Grayzel A I. Miller A E. Endogenous and interferon-augmented natural killer cell activity of human peripheral blood mononuclear cells in vitro. Studies of patients with multiple sclerosis, systemic lupus erythematosus or rheumatoid arthritis. Clin Exp Immunol 1982: 49: 11-21.

24 Grimm E A. Mazumder A. Zhang H, Rosenberg S A. Lymphokine-activated killer cell phenomenon: lysis of natural killer-resistant fresh solid tumor cells by interleukin 2-activated autologous human peripheral blood lymphocytes. J Exp Med 1982: 155: 1823-41.

25 Nabholz M. MacDonald H R. Cytolytic T lymphocytes. Ann Rev Immunol 1983; 1: 273-306.

26 Gaston J S, Rickinson A B, Epstein M A Epstein-Barr virus specific cytotoxic $T$ cell responses in rheumatoid arthritis patients. Rheumatol Int 1982: 2: 155-9.

27 Moss D J, Klestov A, Burrows S. Kane R G. A comparison of 
Epstein-Barr virus-specific T-cell immunity in rheumatoid arthritis and osteoarthritis patients. Aust J Exp Biol Med Sci 1983; 61: 509-16.

28 Highton J. Panayi G S. Spontaneous cytotoxicity of rheumatoid and normal peripheral blood mononuclear cells against 4 human lymphoblastoid cell lines. Ann Rheum Dis 1980; 39: 559-62.

29 Silver R M, Redelman D. Zvaifler N J, Naides S. Studies of rheumatoid synovial fluid lymphocytes. I. Evidence for activated natural killer-like cells. $J$ Immunol 1982; 128: 1758-63.

30 Grimm E A, Ramsey K M. Mazumder A. Wilson D J. Djeu J Y, Rosenberg S A. Lymphokine-activated killer cell phenomenon. II. Precursor phenotype is serologically distinct from peripheral $T$ lymphocytes, memory cytotoxic thymusderived lymphocytes, and natural killer cells. J Exp Med 1983; 157: $884-97$.
31 Grimm E A, Robb R J, Roth J A, et al. Lymphokine-activated killer cell phenomenon. IIl. Evidence that IL-2 is sufficient for direct activation of peripheral blood lymphocytes into $\overrightarrow{\overline{\vec{D}}}$ lymphokine-activated killer cells. J Exp Med 1983; 158: 1356-61.

32 Lefrancois L, Klein J R, Pactkau V. Bevan M J. Antigenindependent activation of memory cytotoxic $T$ cells by interleukin 2. J Immunol 1984; 132: 1845-50.

33 Klein E. Ernberg I. Masucci M G. et al. T cell response to B cells and Epstein-Barr virus antigens in infectious mononucleosis. Cancer Res 1981; 41: 4210-5.

34 Wilkins J A, Warrington R J, Sigurdson S L, Rutherford W J. The demonstration of an interleukin-2 like activity in the synovial fluids of rheumatoid arthritis patients. $J$ Rheumatol 1983; 10: 109-13. 